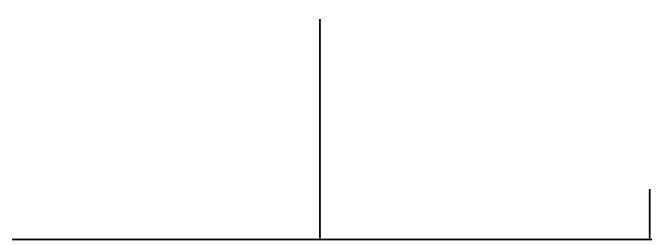

Rev. Latinoam. Psicopat. Fund., São Paulo, v. 15, n. 3, p. 575-589, setembro 2012

\title{
A loucura na fronteira entre a medicina e o direito: a elite médica em busca da legitimação socioprofissional nas páginas do Annaes Brasilienses de Medicina (1860-1880)
}

Monique de Siqueira Gonçalves

Este artigo examina o papel estratégico desempenhado pelo Annaes Brasilienses de Medicina - órgão oficial da Academia Imperial de Medicina -, na busca da elite médica pela legitimação socioprofissional no campo da medicina mental, visando a expansão de suas prerrogativas no âmbito das relações entre loucura, responsabilidade penal, direitos civis e medicina legal de 1860 a 1880.

Palavras-chave: História da medicina, loucura, periodismo médico, direitos civis 


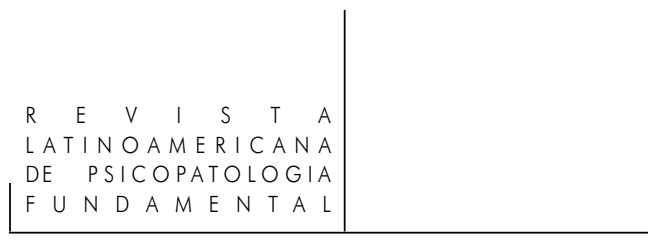

Quantos inocentes não terão sofrido aos rigores da sanção pena, apesar de seus crimes serem o efeito da alienação, e vice-versa? Quantos criminosos não terão sido dispensados de pena legal imposta a seus crimes a título de alienados quando não o são, sem que contudo os peritos possam ser responsáveis perante a sociedade desses fatos, quando se conhece as dificuldades que encontram, ainda mesmo os mais familiarizados em discriminar a loucura simulada da verdadeira (...)

(Rego, 1870, p. 12)

No ano de 1870, em discurso proferido por ocasião do aniversário da Academia Imperial de Medicina, o médico José Pereira Rego, na época presidente dessa instituição, sinalizava para o cerne das disputas que se desenrolavam entre a medicina e o direito - no âmbito da relação entre distúrbios nervosos, em especial a alienação mental, ${ }^{1}$ e direitos civis -, e que se intensificariam nos anos 1870 na capital do Império do Brasil, fazendo deste assunto o foco de muitos debates na Academia.

Entrementes, já no ano de 1867 , elegendo pela primeira vez a questão da medicina legal em seu discurso, pronunciado na presença do imperador Pedro II, Pereira Rego destacava, apoiando-se em Ambroise Tardieu (médico-legista francês), a necessidade da utilização, por meio do legislador ou magistrado, do conhecimento médico para a solução de casos que necessitassem de uma aplicação dos dados da fisiologia, da medicina e da cirurgia (Rego, 1867, p. 68-79). Rego ressaltava, neste pronunciamento, o que, para ele, consistia um

1. A palavra "nevrose" foi sistematicamente utilizada nas teses médicas defendidas na Faculdade de Medicina do Rio de Janeiro e correspondia à névrose, conceito utilizado por Pinel (Bercherie, 1989) e traduzido para a língua portuguesa como nevrose ou neurose. A palavra "nevrose" caracterizava as doenças do sistema nervoso que não apresentavam lesões orgânicas apreciáveis, dentre as quais constavam a epilepsia, a histeria, a alienação mental (mania, melancolia etc.), além de outras moléstias nervosas.

Rev. Latinoam. Psicopat. Fund., São Paulo, v. 15, n. 3, p. 575-589, setembro 2012 
desprezo por parte do código penal, quando não previa a utilização deste conhecimento especial, que somente o profissional da medicina detinha, na confecção das leis penais. ${ }^{2}$ Assim, esse proeminente acadêmico conferia destaque a um assunto abordado, desde meados dos anos 1860, nas páginas do Annaes Brasilienses de Medicina, periódico oficial da Academia Imperial de Medicina, dando ênfase à falta de ingerência dos médicos nos julgamentos que envolviam a responsabilidade penal de crimes possivelmente cometidos sob estados mentais patológicos.

Devemos destacar que, apesar do Código Penal Brasileiro de 1830 ter tornado obrigatório que juízes de direito ouvissem médicos peritos antes de proferirem sentenças criminais, a interferência de médicos, em julgamentos criminais envolvendo possíveis doentes mentais, somente se consolidou no final do século XIX. Conjuntura que decorria, em primeiro lugar, do status da medicina acadêmica nos Oitocentos, pois, apesar da medicinal legal ser dotada de uma cadeira desde a inauguração da Faculdade de Medicina do Rio de Janeiro, no ano de 1832, ela não gozou de prestígio até fins do século XIX (Corrêa, 1998), devido, sobretudo, à falta de aparato técnico para a realização de exames. Circunstância que era agravada, em segundo lugar, pela tardia criação da cadeira de Clínica Psiquiátrica e Moléstias Mentais, em 1881, por meio de um decreto que ampliava a Reforma Leôncio de Carvalho, aprovada no ano de 1879 (Edler, 1992). Entretanto, apesar da inexistência de alienistas formados pelas faculdades do Império do Brasil, fora se conformando ao longo da segunda metade do século, no âmbito da prática clínica, um corpo de médicos clínicos dedicados ao tratamento de distúrbios nervosos, dentre os quais figuravam, no Rio de Janeiro, os médicos que atuavam no serviço sanitário do Hospício Pedro II, em Casas de Saúde especializadas, como a Casa de Saúde do Dr. Eiras, e em consultórios e clínicas médicas especializadas, como a Clínica de Moléstias Mentais e Nervosas, na qual atuava o Dr. Augusto Costa, que se denominava especialista em "afecções mentais e nervosas"3. Além

2. Como argumentaria criticamente o psiquiatra Teixeira Brandão, em 1886, o Código Criminal do Império era falho por não prever a presença de um legista competente em alienação para atestar o discernimento do criminoso no momento do crime, dando ao juiz um poder excessivo e arbitrário (Cf. Machado et al., 1978, p. 481).

3. Em 1875, 1876 e 1877 o nome do dr. Augusto Costa constava na lista de médicos que atuavam na cidade do Rio de Janeiro, publicada anualmente pelo Almanak Laemmert. A partir do segundo ano, também configurava, na seção de Notabilidades, uma propaganda da denominada "Clínica de moléstias mentais e nervosas", na qual se afirmava que o Dr. Augusto Costa havia se dedicado a estudar "as diversas formas de afecções mentais e nervosas" em hospícios e casas de saúde especiais de Paris e Londres, e que tinha frequentado a clínica do Dr. Magnan, no Asilo de Santana (Hospital Saint-Anne, na França).

Rev. Latinoam. Psicopat. Fund., São Paulo, v. 15, n. 3, p. 575-589, setembro 2012 
destes, uma série de médicos clínicos - entre os quais figuravam alguns membros da Academia Imperial de Medicina, a exemplo dos médicos José Luiz da Costa e Nicoláu Joaquim Moreira - se dedicariam ao estudo de doenças nervosas, haja vista que mesmo diante da inexistência de uma formação especializada no Império, tais moléstias também eram objeto de estudo da Faculdade de Medicina do Rio de Janeiro, se conformando como uma área de crescente interesse desta categoria profissional $^{4}$ (Gonçalves, 2011).

Assim, analisamos neste artigo os primórdios de uma luta jurisdicional ${ }^{5}$ entre a medicina e o direito, capitaneada por membros da elite médica, ${ }^{6}$ a partir dos anos de 1860, centrando-nos na análise dos discursos proferidos pelos médicos acadêmicos por meio de seu principal veículo de comunicação, o Annaes Brasilienses de Medicina, com vistas à extensão das suas prerrogativas socioprofissionais no tocante às relações entre direito, medicina legal e alienação mental.

Dessa forma, selecionamos duas matérias publicadas no Annaes Brasilienses de Medicina $^{7}$ para a realização da presente análise, sendo a primeira uma $\mathrm{Me}$ -

4. O crescente número de teses médicas apresentadas à Faculdade de Medicina do Rio de Janeiro sobre esta temática, por meio das Cadeiras de Patologia Médica, Clínica Médica e Medicina Legal corrobora esta perspectiva.

5. Tomando como base o arcabouço teórico desenvolvido por Andrew Abbott no livro The systems of professions (1998), concebemos que a atuação dos médicos brasileiros, de 1850 a 1880, se voltava para a busca de uma definição etiológica das moléstias nervosas, visando a expansão e à consolidação de perspectivas socioprofissionais, haja vista que, como adverte Abbott, as profissões se desenvolvem em torno de suas relações interprofissionais e de seu conteúdo técnico, na luta pelo monopólio jurisdicional.

6. A elite médica não é formada necessariamente pelos melhores médicos, mas por aqueles indivíduos que tradicionalmente concentram em suas mãos os diferentes tipos de poder profissional. Sobre o conceito de elite médica ver: Weisz, 1988.

7. O Annaes Brasilienses de Medicina, periódico editado pela Academia Imperial de Medicina, instância subordinada diretamente ao governo imperial e sustentada por subvenção pública, apresentara-se, durante todo o período, como um órgão representativo das expectativas corporativas desta instituição. Neste âmbito, assuntos relativos à higiene pública, à legitimidade profissional e à medicina nacional seriam o foco dos artigos publicados nesse periódico, que se voltava para o governo monárquico em busca de apoio e consolidação das perspectivas profissionais de parte da elite médica carioca, em torno da legitimação da medicina acadêmica. Os editores responsáveis por este periódico eram eleitos anualmente entre os membros da Academia que se candidatavam, sendo o conteúdo nele divulgado definido por tais acadêmicos. Com exceção dos debates quinzenais ocorridos na Academia, que eram sempre publicados nas primeiras páginas do periódico, e das Memórias apresentadas à Academia por médicos interessados em participar desta corporação, a escolha das demais matérias ficava sob sua total

Rev. Latinoam. Psicopat. Fund., São Paulo, v. 15, n. 3, p. 575-589, setembro 2012 
mória ${ }^{8}$ apresentada em 1869 à Academia Imperial de Medicina e a segunda uma Consulta ${ }^{9}$ recebida pela Academia em 1876. A partir destas ${ }^{10}$ objetivamos analisar os primórdios da luta pela legitimação socioprofissional da medicina nesta área da medicina legal, com ênfase para o papel essencial desempenhado pelo periodismo médico especializado na conformação de uma opinião pública favorável à atuação da elite médica nessa esfera (Edler, 1992; Ferreira, 1996; Gonçalves, 2011).

Os dois casos eleitos - em meio a uma extensa gama de fontes levantadas e analisadas - foram avaliados por nós como casos exemplares, a partir dos quais acreditamos ser possível destacar os indícios de uma disputa socioprofissional que se desenrolara no meio acadêmico, de 1860 ao final da década de 1880 . Tal seleção também resulta de uma análise comparativa realizada previamente entre as matérias publicadas no Annaes Brasilienses de Medicina e aquelas veiculadas nos periódicos médicos de iniciativa privada, editados de 1850 a 1880. Partimos da verificação de que, diferentemente do que ocorrera no Annaes, nos periódicos particulares esta temática não esteve presente em nenhum artigo, sendo todas as matérias neles publicadas a respeito das doenças nervosas, voltadas para a apresentação de observações realizadas no âmbito da clínica médica. Assim, ao nosso ver, o envolvimento de médicos acadêmicos nesta querela com o direito, expressa nas páginas do jornal da Academia, nos indica o papel evidentemente político exercido por estes médicos que, face ao poder, como representantes oficiais de uma categoria profissional, buscavam expandir suas prerrogativas na área da medicina legal, e para isso utilizavam as páginas deste periódico como divulgador e legitimador de suas expectativas.

responsabilidade, cabendo ao editor selecionar artigos de seus pares, além de traduzir e comentar artigos publicados em jornais estrangeiros, segundo sua preferência. De forma geral, o perfil desta publicação apresentava sensíveis variações de temáticas, dependendo do editor responsável (Gonçalves, 2011).

8. Eram denominadas Memórias os trabalhos monográficos, de cunho científico, apresentados por médicos brasileiros ou estrangeiros à Academia Imperial de Medicina, com o objetivo de fazerem parte do corpo acadêmico, seja como membros honorários, titulares, adjuntos ou correspondentes.

9. A Academia Imperial de Medicina realizava quinzenalmente sessões públicas nas quais eram apresentadas comunicações e realizados debates pelos seus membros, sendo aberto ao público a apresentação de Consultas para a confecção de pareceres médicos referentes a questões de saúde pública.

10. A análise realizada neste artigo se restringiu às duas matérias selecionadas devido ao espaço de publicação, mas foi motivada pela divulgação de diversas matérias sobre a mesma temática no Annaes Brasilienses de Medicina durante o período estudado, o que denotou, para nós, o intenso esforço de legitimação empreendido pela elite médica na área da medicina legal. 
Finalmente, tendo em vista a relevância política e sociocultural angariada pelos impressos desde o fim da censura prévia à imprensa em 1821, intentamos, neste artigo, analisar a palavra impressa como uma "força ativa na história" e não como um simples registro do que aconteceu (Darton; Roche, 1996) e, neste sentido, também somos conduzidos para a tentativa de compreender a racionalidade e intencionalidade dos discursos produzidos, cientes de que estes são sempre marcados pelo "meio-silêncio que o precede" (Foucault, 2005). Ou seja, analisando os discursos veiculados pelos meios de comunicação impressos, procuraremos nos debruçar sobre o papel exercido por eles, atentando para a complexidade inerente às intenções dos atores historicamente situados.

\section{A busca pela legitimação socioprofissional por meio das fronteiras}

Em 1869, uma Memória apresentada à Academia Imperial de Medicina, pelo médico belga J. Parigot, professor honorário da Universidade de Bruxelas, abarcava os principais aspectos apresentados pelo debate que envolvia a questão da responsabilidade legal dos alienados e que se sucedia tanto na Europa quanto no Brasil. As divergências entre alienistas e jurisconsultos quanto à punição de um possível ato criminoso cometido sob um estado mórbido, sob o qual o indivíduo não teria o controle de suas vontades, era o foco deste trabalho.

Centrando a sua análise em torno da questão do livre-arbítrio, Parigot apresentava uma reflexão acerca da relação entre instinto e moral, advertindo que na falta do senso moral e da educação, o homem estaria entregue às paixões, não podendo ser responsabilizado, nestas condições, por possíveis atos criminosos que viesse a cometer. A educação moral, desta forma, exerceria um papel fundamental em sua análise visto que seria por meio desta que um indivíduo, em vez de se entregar aos instintos animais, poderia adquirir princípios que the possibilitassem o pleno exercício do livre-arbítrio. Defendia, assim, que não se poderia chamar à responsabilidade alguém que estivesse em uma condição material que impedisse a liberdade de consciência, como no caso daquele que abusasse de álcool ou de drogas e que, ao cometer um crime, estivesse com o seu livre-arbítrio voluntariamente oprimido.

A análise de Parigot era baseada na ideia de que não se poderia aplicar a mesma noção de responsabilidade, perante as leis penais, a todos os indivíduos, e que, no caso da ocorrência de um delito, o indivíduo que o cometesse deveria ser analisado por um profissional médico, para que fosse verificado se gozava de perfeito uso de suas faculdades volitivas. O diagnóstico da alienação mental

Rev. Latinoam. Psicopat. Fund., São Paulo, v. 15, n. 3, p. 575-589, setembro 2012 
estaria, assim, relacionado com a incapacidade do "criminoso" de conter os seus instintos animais.

Parigot defendia a criação de um conceito que cunhava de diastrefia, para denominar uma doença de caráter moral, na qual o indivíduo não apresentava nenhum tipo de delírio, mas somente uma profunda perversão dos seus sentimentos, que de forma alguma se dava por um instinto ingovernável. Em se tratando do conceito de diastrefia, definia, resumidamente, que a causa principal da ausência do controle da vontade e do poder de exame estava na falta da educação e da moral. Neste sentido, filhos mal- educados seriam, muitas vezes, futuros alienados perversos.

Após dissertar sobre as suas concepções médicas acerca das manifestações das diferentes formas de loucura, Parigot defendia dois pontos: primeiro, que o hospício e o alienista deveriam ser os principais agentes terapêuticos nas manifestações de alienação mental e, segundo, que se deveria dar maior atenção à importância delegada aos loucos nos códigos penais, tanto da França quanto do Brasil, tendo em vista que os processos criminais apresentariam verdadeiras questões de psicologia sã ou mórbida a serem analisadas, pois estas definiriam a responsabilidade ou não do réu sobre os seus atos.

Tanto sob a perspectiva terapêutica quanto penal, Parigot colocava os alienados sob a tutela dos médicos, os quais deveriam decidir tanto sobre os aspectos que se referiam ao processo de cura da patologia mental quanto acerca da metodologia de julgamento de um crime. Quem, a não ser o médico, poderia asseverar que um indivíduo tinha ou não cometido um crime sob o impulso de um estado mórbido? Que outro profissional estaria apto a, de forma dócil e cientificamente baseada, acompanhar o processo de cura e educação moral de um alienado? Estes eram os principais argumentos defendidos por Parigot e que foram, sem dúvida, os argumentos dos discursos proferidos por outros médicos brasileiros na década de 1870 .

Nicoláu Joaquim Moreira, médico acadêmico, em relatório produzido sobre a Memória deste esculápio (Moreira, 1869), ressaltava a contribuição dada por Parigot visto que este ratificava as ideias apresentadas por alguns médicos brasileiros, dentre os quais se incluía, ao sustentar a importância dos estudos médicos-legais e a necessidade de criação de um júri médico que atuaria em julgamentos criminais.

Apoiando-se em autores como Briand, Casper, Davergie, Esquirol, Legrand du Saulle, Pinel, Georget, Perchappe e Lelut, defendia, corroborando a tese apresentada por Parigot, que a desordem das faculdades mentais começava sempre pelo lado afetivo e moral, sendo o delírio dos pensamentos e das palavras, assim como a desordem das ações, puramente a expressão do delírio da vontade. A necessidade do estudo das monomanias afetivas e das monomanias instintivas 
com ou sem delírio seriam centrais para este acadêmico, visto que serviriam para esclarecer fatos relacionados à responsabilidade penal e civil, que ainda apresentavam dissensos entre alienistas e jurisconsultos. A seguir, ressaltava que a questão da responsabilização penal estava sub judice, pois era uma polêmica tanto entre jurisconsultos como por parte de alienistas que discordavam quanto à necessidade de aplicação da responsabilidade parcial, proporcional ou condicional segundo cada caso.

Não há neste relatório, a sinalização de nenhuma solução imediata para tais discordâncias, a não ser a indicação da necessidade de aprofundamento dos estudos sobre as moléstias mentais pela categoria médica; mas, por meio deste, podemos adentrar nesta querela percebendo que a própria indefinição no campo do alienismo repercutia na falta de credibilidade junto aos processos judiciais. Ademais, a publicação, no Annaes Brasilienses de Medicina, dos pronunciamentos do presidente da Academia, assim como da Memória acima analisada, demonstram o esforço empreendido pela corporação médica oficial no alargamento das prerrogativas da medicina na área da medicina legal. Aspecto que podemos também perceber quando da análise das consultas feitas à Academia, a exemplo do caso que trataremos adiante.

\section{O caso de Alexandre da Costa Silveira - quem está apto a diagnosticar a loucura?}

Alexandre da Costa Silveira, em sessão de 17 de abril de 1876, solicitava aos membros da Academia Imperial de Medicina que fosse submetido a um exame de sanidade, com a seguinte Consulta: "Em defesa da minha liberdade, direito e pessoa, venho impetrar da ilustrada corporação a graça de fazendo-me passar por um exame severo, declarar: 1) Se estou no gozo de minhas faculdades mentais? 2) Se o médico da polícia, do modo por que procedeu, estava autorizado a declarar-me alienado?" (Editorial, 1878, p. 378).

Ocorreu que, na noite de 15 de novembro de 1875, Alexandre Silveira fora recolhido ao xadrez da polícia da Corte, por provocar transeuntes atirando garrafas e outros objetos e por "praticar atos imorais". Segundo o subdelegado, o preso apresentava todos os indícios de que sofria de alienação mental, e por isso, com ordens do chefe de polícia, solicitara ao médico perito que o examinasse para que fosse diagnosticado se era mesmo louco. Neste exame, o sobredito médico ratificava a suspeita, afirmando que Alexandre sofria "de suas faculdades mentais em consequência do abuso de bebidas alcoólicas" e, por conseguinte, recomendava que o preso permanecesse detido no xadrez por mais um dia. Em

Rev. Latinoam. Psicopat. Fund., São Paulo, v. 15, n. 3, p. 575-589, setembro 2012 
outro exame, no dia 17, o mesmo médico confirmava o laudo, observando, porém, que o "paciente" estava perfeitamente calmo.

Alexandre permaneceu preso no xadrez da polícia até o dia 26, quando o inspetor desta instituição requereu ao chefe da polícia a sua remoção para o Hospício Pedro II, alegando que o mesmo sofria "de vez em quando de acessos de furor com tal intensidade que forçoso era conservá-lo em camisola de força" (Editorial, 1878, p. 381). Desta data até o dia 4 de dezembro, Alexandre permaneceu no asilo de mendigos quando, em resposta ao pedido de transferência, o provedor da Santa Casa de Misericórdia respondeu que na opinião do médico diretor do serviço sanitário, ${ }^{11}$ por quem Alexandre tinha sido examinado, este deveria ser removido para o Hospício Pedro II, local em que ficou internado até o dia 10 de março de 1876. Desde a sua prisão até a data da sua alta do hospício foram contabilizados 115 dias de privação de sua liberdade por suspeita de loucura.

O relatório produzido por ocasião desta Consulta, organizado pelos médicos da Academia Imperial de Medicina, Francisco da Costa Ferraz, João Pinto do Rego César, Manoel Alves da Costa Brancante e José Pereira Rego Filho (Editorial, 1878), afirmava que os pareceres dos dias 17 e 18 de novembro de 1875 , feitos pelo perito policial, não poderiam ser contemplados como documentos médicolegais, visto que não tinha sido realizado um verdadeiro exame em nenhuma das duas ocasiões. Depois de 15 dias de observação do indivíduo em questão, a comissão nomeada pela Academia concluía que Alexandre estava em perfeito estado de saúde. Os responsáveis pelo relatório mencionavam que, em visita ao Hospício Pedro II, foram informados, pelos doutores Ignácio Francisco Goulart e José Custódio Nunes, que o paciente a princípio apenas se mostrara tristonho, melancólico, não querendo alimentar-se, mas que nunca denunciara qualquer indício de perturbação cerebral. Mesmo na anotação feita no livro de observações acerca de Alexandre, constava uma interrogação na casa relativa ao diagnóstico e inclusive as irmãs e enfermeiras, que com ele estiveram, concordavam com a opinião de que o mesmo permanecera tranquilo e íntegro em suas faculdades mentais.

Em defesa do médico do hospício, os acadêmicos afirmavam que este não poderia crer que o médico perito da polícia condenaria como louco um "cidadão no uso e gozo de todos os seus direitos" (Editorial, 1878, p. 384), e que pela honra de seu colega, optara reservar-se para um estudo mais detido do estado do paciente.

11. No ano em questão era médico diretor responsável pelo serviço sanitário do Hospício Pedro II, o Dr. Ignácio Francisco Goulart.

Rev. Latinoam. Psicopat. Fund., São Paulo, v. 15, n. 3, p. 575-589, setembro 2012 
Em apoio à defesa dos médicos do Hospício Pedro II transcreviam também uma carta publicada no Jornal do Commercio, escrita por Ignácio Francisco Goulart (Goulart, 1878), datada de 15 de abril de 1876. Nesta dr. Goulart narrava que quando foi ao asilo de mendigos para dar execução ao despacho do provedor da Santa Casa de Misericórdia, encontrara Alexandre Silveira desfiando estopa, parecendo-lhe muito tranquilo, conquanto estivesse merencório, e tendo em vista a informação recebida no ofício que tinha em seu poder, propôs que fosse recolhido ao hospício. Em seguida, sublinhava que era importante informar ao público que, conforme regimento do Hospício Pedro II, os indivíduos ali admitidos eram postos em observação até que o médico pudesse se informar definitivamente sobre o seu estado mental, e que qualquer paciente dava entrada com matrícula somente quando o provedor ordenava, tendo em vista o parecer do médico.

Sobre o estado apresentado por Alexandre destacava que seu comportamento era taciturno, hipocondríaco; que este se recusava a se alimentar e fazia todos os esforços para ficar em isolamento, declarando que não comeria e que morreria de fome se não o pusessem em liberdade. Dessa forma, redarguia aqueles que o acusavam demonstrando as dificuldades de se fazer um diagnóstico em casos como este, apoiando-se em um fato ocorrido com o renomado alienista francês Tardieu, que observara um indivíduo por mais de um ano, só porque a justiça suspeitava de sua integridade mental.

Logo, defendia que não poderia ser censurado pela reclusão de Alexandre já que tinha em mãos informações oficiais sobre tal indivíduo, que lhe fizeram tentar conciliar "o respeito à liberdade individual com a garantia social". Prosseguia sua defesa, assegurando que para aquele que entendia de patologia mental e cumpria os seus deveres conscienciosamente, um ligeiro exame, sem informações pessoais, como acontecia com os pacientes levados ao asilo e ao Hospício Pedro $\mathrm{II},{ }^{12}$ não se tinha o suficiente para julgar sobre o estado mental de qualquer pessoa, mesmo nos casos mais simples. Em qualquer caso, somente uma observação continuada poderia guiar o alienista no descobrimento da verdade. Finalizava a sua explanação dizendo a Alexandre que "se não tivesse sido removido para o hospício estaria ainda hoje no asilo de mendigos desfiando estopa, se não estivesse já na eternidade" (Goulart, 1878, p. 438).

Em seguida à reprodução da querela desenvolvida entre Alexandre e os médicos da polícia e do hospício, os acadêmicos responsáveis pelo relatório acionavam um leque de referenciais teóricos, para estabelecerem um guia para a

12. O médico diretor do Hospício Pedro II repetia nesta passagem as reclamações feitas pelo anterior diretor do estabelecimento, Manoel José Barbosa, a respeito da falta de informações sobre os pacientes. Sobre este assunto ver Gonçalves, 2011, p. 45.

Rev. Latinoam. Psicopat. Fund., São Paulo, v. 15, n. 3, p. 575-589, setembro 2012 
produção de um diagnóstico acertado acerca das moléstias mentais, especificamente daquelas referentes ao abuso de bebidas alcoólicas. Citando Adolpho Chauveau e Faustino Helie, entre outros, defendiam a imprescindibilidade da cautela na análise de réus consumidores de bebida, advertindo que se deveria levar em consideração aspectos como a quantidade ingerida, a tolerância ao álcool, a natureza do delito cometido e os hábitos de vida do indivíduo.

Segundo os esculápios, no que se referia a Alexandre, a detecção do delirium tremens não seria difícil, pois esta moléstia comumente acometia os indivíduos que, por muito tempo, abusavam de bebidas alcoólicas, caracterizando-se, principalmente, pelas perturbações das funções nervosas, insônia, delírio e alucinações de natureza particular, além do tremor dos membros, com ou sem febre. Além disto, pautavam-se nestes referenciais para censurar, diretamente, a forma como a polícia da Corte estava agindo, ao enviar supostos alienados mentais para o asilo de mendigos, local onde não se poderia aplicar sequer o tratamento moral preconizado por grande soma de autores.

Sob o aspecto analítico, a longa lista de referenciais por eles utilizada revela-nos a intensidade dos contatos intelectuais travados no meio acadêmico. Além disto, esta longa explanação nos possibilita compreender também a forma como o conhecimento era produzido no meio acadêmico. A fim de responderem aos quesitos propostos, acionava-se uma série de autores, cuja autoridade servia como lastro para corroborar um ponto de vista apresentado, reforçando a legitimidade do argumento.

No entanto, essa polêmica não se restringira ao meio acadêmico, pois como já sinalizamos anteriormente, cartas foram publicadas no Jornal do Commercio, além do episódio ter se tornado objeto de sátira nas páginas da Revista Ilustrada, de propriedade do jornalista e caricaturista italiano Angelo Agostini. Nesta última, na edição de 22 de abril de 1876, três de suas oito páginas eram dedicadas ao caso de Alexandre da Costa, cuja saga era narrada por meio de caricaturas e críticas aos médicos do Hospício Pedro II e da Academia Imperial de Medicina. Agostini satirizava a falta de legitimidade profissional dos médicos, deixando implícito que tal situação se dava pela indefinição das concepções científicas da própria medicina.

\section{Conclusões}

Se por um lado, as querelas aqui apresentadas demonstram um momento no qual as categorias nosológicas sobre as doenças nervosas ainda buscavam a sua consolidação, por outro demonstram o grande esforço realizado pelos membros 
da elite médica em expandir as suas prerrogativas socioprofissionais, por meio de debates e discursos que visavam reforçar a importância do conhecimento médico na definição de diagnósticos capazes de definir a imputabilidade ou não de um indivíduo que cometera um crime, ou mesmo influir na decisão sobre o "sequestramento" de um suposto alienado ao hospício, antecedendo as disputas profissionais mais intensas que culminaram na formação do manicômio judiciário na passagem do século (Carrara, 1998; Peres e Nery, 2002).

Sobretudo, devemos destacar a centralidade do papel exercido pela imprensa na segunda metade do século XIX, utilizada tanto como instrumento de legitimação profissional - no caso da publicação de periódicos médicos especializados como o Annaes Brasilienses de Medicina -, como espaço de expressão de opiniões públicas divergentes, a exemplo do caso da utilização das páginas dos jornais da "grande imprensa" para a realização de debates públicos. De maneira geral, tais embates nos atentam para a importância angariada pela imprensa e, consequentemente, pela opinião pública nos oitocentos, nos lembrando que tais fontes ainda podem contribuir muito para a produção de conhecimento a respeito dos primórdios da psiquiatria no Brasil.

\section{Fontes Primárias}

EDitorial. Sofrimento das faculdades mentais, em consequência do abuso de bebidas alcoólicas. Annaes Brasilienses de Medicina, Rio de Janeiro, tomo XXIX, n. 10, p. 378-398, mar. 1878.

Goulart, I. F. Carta. Annaes Brasilienses de Medicina, Rio de Janeiro, tomo XXIX, n. 10, p. 437-438, abr. 1878.

MoreIRA, N. J. Relatório do Sr. Dr. Nicoláo Joaquim Moreira acerca da memória do Sr. Dr. J. Parigot sobre A loucura moral ou a mania sem delírio, lido e aprovado na sessão de 15 de março de 1869. Annaes Brasilienses de Medicina, Rio de Janeiro, tomo XXI, n. 3, p. 93-98, ago. 1869.

Notabilidades. Clínica de moléstias mentais e nervosas. Almanak Laemmert, Rio de Janeiro, p. 23, 1876.

PARIGOT, J. Sobre uma doença mental chamada em diversas línguas Folie morale, moral insanity, Gemuthskrunkeit, manie sans delire, folie lucide, folie raisonnante, folie instinctive (...). Annaes Brasilienses de Medicina, Rio de Janeiro, tomo XXI, n. 2, p. 55-82, jul. 1869.

Rego, J. P. Discurso pronunciado pelo Exm. Sr. Dr. José Pereira Rego, na sessão aniversária da Academia Imperial de Medicina, em 30 de junho de 1870. Annaes

Rev. Latinoam. Psicopat. Fund., São Paulo, v. 15, n. 3, p. 575-589, setembro 2012 
Brasilienses de Medicina, Rio de Janeiro, tomo XXII, n. 1, p. 6-14, jun. 1870

Rego, J. P. Discurso proferido na sessão aniversária de 30 de junho de 1867 com a presença do Imperador Pedro II. Annaes Brasilienses de Medicina, Rio de Janeiro, tomo XVIII, n. 2, p. 68-79, jul. 1867.

\section{Referências}

Аввотт, A. The system of professions. An essay on the division of expert labor. Chicago and London: The University of Chicago Press, 1988.

CARrara, S. Crime e loucura: o aparecimento do manicômio judiciário na passagem do século. Rio de Janeiro/São Paulo: Eduerj/Edusp, 1998.

CorrêA, M. As ilusões da liberdade: a Escola Nina Rodrigues e a antropologia no Brasil. Bragança Paulista: Edusf, 1998.

Darton, R.; Roche, D. (Orgs.). Revolução Impressa: a imprensa na França de 1775 a 1880. São Paulo: Edusp, 1996.

EDLER, F. C. As reformas do ensino médico e a profissionalização da medicina na Corte do Rio de Janeiro (1854-1884). 1992. 297 p. Dissertação (mestrado em História), Universidade de São Paulo - USP, São Paulo, 1992.

Ferreira, L. O. O nascimento de uma instituição científica: os periódicos médicos brasileiros da primeira metade do século XIX. 1996. 209 p. Tese (doutorado em História), Universidade de São Paulo - USP, São Paulo, 1996.

Foucault, M. Arqueologia das ciências e história dos sistemas de pensamento. Rio de Janeiro: Forense Universitária, 2005.

Gonçalves, M. de S. Mente sã, corpo são: disputas, debates e discursos médicos na busca pela cura das "nevroses" e da loucura na Corte imperial (1850-1880). 2011. 244p. Tese (doutorado em História das Ciências e da Saúde), Fundação Oswaldo Cruz, Casa de Oswaldo Cruz, Rio de Janeiro, 2011.

Machado, R. et al. Danação da norma: medicina social e constituição da psiquiatria no Brasil. Rio de Janeiro: Graal, 1978.

Peres, M. F. T.; Nery Filho, A. A doença mental no direito brasileiro: ininputabilidade, irresponsabilidade, periculosidade e medida de segurança. História, Ciências, Saúde - Manguinhos, Rio de Janeiro, vol. 9, n. 2, p. 335-355, maio-ago. 2002.

WeIsz, G. Les transformations de l'Elite medicale em France. Actes de la Recherche en Sciences Sociales, n. 74, p. 33-46, sept. 1988. 


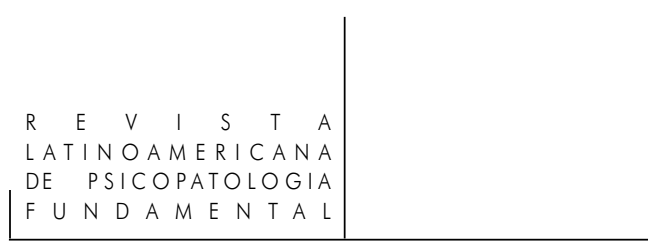

\section{Resumos}

(Madness, penal responsibility, civil rights and forensic medicine: the medical elite in search of socio-professional legitimation in the pages of Annaes Brasilienses de Medicina (Brazilian Annals of Medicine)

This article examines the strategic role played by the Brazilian Annals of Medicine, the official organ of the Imperial Academy of Medicine. Its objective was to socially legitimize the medical elite in the field of mental health. It sought to broaden its prerogatives in the area of madness, criminal liability, civil rights and forensic medicine between 1860 and 1880.

Key words: History of medicine, madness, medical journalism, civil rights

(La folie entre la médicine et le droit: l'élite médicale à la poursuite de la légitimation socioprofessionnelle au cours des pages des Annales Brésiliennes de Médicine (18601880)

Cet article examine le rôle stratégique des Annaes Brasilienses de Medicina (Annales Brésiliennes de Médicine) - organe officiel de l'Académie Impériale de Médicine - pour l'élite médicale à la recherche d'une légitimation socioprofessionnelle dans le domaine de la médicine mentale visant à étendre ses prérogatives par rapport à la folie, la responsabilité pénale, les droits civils et la médicine légale de 1860 à 1880.

Mots clés: Histoire de la médicine, folie, presse médicale, droits civils

(La locura en la frontera entre la medicina y el derecho: la élite médica en la búsqueda de la legitimación sócio-professional en las páginas de los Anales Brasilienses de Medicina (1860-1880))

Este artículo examina el papel estratégico desempeñado por los Anales de Medicina Brasilienses - órgano oficial de la Academia Imperial de Medicina -, en la búsqueda de la élite médica por la legitimación sócio-profesional en el campo de la medicina mental, com el objetivo de expandir sus prerrogativas en el ámbito de la relación entre locura, responsabilidad penal, derechos civiles e medicina legal desde 1860 hasta 1880.

Palabras clave: Historia de la medicina, locura, periodismo médico, derechos civiles

(Wahnsinn, strafrechtliche Verantwortlichkeit, Bürgerrechte und Rechtsmedizin: Die ärztliche Elite auf der Suche nach der sozial-beruflichen Legitimierung auf den Seiten der Annaes Brasilienses de Medicina (1860-1880))

In diesem Beitrag wird die strategische Rolle der Annaes Brasilienses de Medicina - eine offizielle Veröffentlichung der Imperialen Akademie für Medizin - dargestellt, auf der Suche nach sozial-beruflicher Legitimierung der medizinischen Elite im Bereich der geistigen Gesundheit, in Hinblick auf die Ausweitung ihrer Vorrechte im Bereich der

Rev. Latinoam. Psicopat. Fund., São Paulo, v. 15, n. 3, p. 575-589, setembro 2012 
Beziehungen zwischen Wahnsinn, strafrechtlicher Verantwortung, Bürgerrechte und Rechtsmedizin von 1860 bis 1880.

Schlüsselwörter: Geschichte der Medizin, Wahnsinn, ärztliche Zeitschriften, Bürgerrechte.

Citação/Citation: GonçALVES, M. DE S. A loucura na fronteira entre a medicina e o direito: a elite médica em busca da legitimação socioprofissional nas páginas do Annaes Brasilienses de Medicina (1860-1880). Revista Latinoamericana de Psicopatologia Fundamental, São Paulo, v. 15 , n. 3, p. 575-589, setembro 2012 .

Editor do artigo/Editor: Prof. Dr. Paulo Dalgalarrondo e Profa. Dra. Ana Maria G. R. Oda

Recebido/Received: 13.12.2011 / 12.13.2012 Aceito/Accepted: 25.5.2012 / 5.25.2012

Copyright: () 2009 Associação Universitária de Pesquisa em Psicopatologia Fundamental/ University Association for Research in Fundamental Psychopathology. Este é um artigo de livre acesso, que permite uso irrestrito, distribuição e reprodução em qualquer meio, desde que o autor e a fonte sejam citados / This is an open-access article, which permits unrestricted use, distribution, and reproduction in any medium, provided the original author and source are credited.

Financiamento/Funding: Esta pesquisa é financiada pela Fundação Oswaldo Cruz e Fundação Carlos Chagas Filho de Amparo à Pesquisa do Estado do Rio de Janeiro - Faperj / This research is funded by the Oswaldo Cruz Foundation and Carlos Chagas Filho Foundation of Support to Research of the Rio de Janeiro State - Faperj.

Conflito de interesses/Conflict of interest: A autora declara que não há conflito de interesses / The author declares that has no conflict of interest.

\section{Monique de Siqueira Gonçalves}

Pós-doutoranda do Programa de Pós-Graduação em História da Universidade do Estado do Rio de Janeiro - UERJ (Rio de Janeiro, RJ., Br), sob a supervisão da Prof. ${ }^{\text {a }}$ Dr. ${ }^{a}$ Tânia Maria Tavares Bessone da Cruz Ferreira, com pesquisa financiada pela bolsa de pós-doutorado da Fundação Carlos Chagas Filho de Amparo à Pesquisa do Estado do Rio de Janeiro - Faperj; Doutora em História das Ciências e da Saúde pela Casa de Oswaldo Cruz - Fiocruz (Rio de Janeiro, RJ, Br), com tese intitulada Mente sã, corpo são: disputas, debates e discursos médicos na busca pela cura das "nevroses" e da loucura na Corte imperial (1850-1880), defendida em 2011, orientada pelo Prof. Dr. Flavio Coelho Edler e disponível em: http://www.fiocruz.br/ ppghcs/media/tese_monique_siqueira.pdf.

Universidade do Estado do Rio de Janeiro - IFCH

Laboratório Redes de Poder e Relações Culturais

Rua São Francisco Xavier, 524, sala 9024, Bloco B - Maracanã

20550-900 Rio de Janeiro, RJ, Br

e-mail: monique.eco@gmail.com

Rev. Latinoam. Psicopat. Fund., São Paulo, v. 15, n. 3, p. 575-589, setembro 2012 